\title{
Rosalina Ríos Zúñiga y Juan Leyva, coords. (2015), Voz popular, saberes no oficiales: humor, protesta, disidencia y organización desde la escuela, la calle y los márgenes (México, siglo XIX), IISUE, UNAM, México
}

\section{Anne Staples}

El Colegio de México astaples@colmex.mx

El saber leer y escribir como requisito para ejercer los derechos de la ciudadanía (la línea divisoria entre la cultura escrita y la oral), el concepto de hombre civilizado frente al hombre rural y las definiciones desdibujadas de habla culta y habla popular forman el contexto histórico de trasfondo del libro Voz popular..., cuyo título indica las diferentes partes que lo componen. La obra se divide temáticamente en catorce capítulos, más las introducciones metodológicas de Rosalina Ríos Zúñiga y Juan Leyva. En la primera, Rosalina Ríos recorre extensamente los trabajos clásicos y recientes acerca de la recepción de la lectura, de la mutua influencia entre la cultura letrada y la iletrada, de cómo los proyectos educativos decimonónicos retomaron los ideales de la ilustración (de crear ciudadanos conocedores de sus derechos y obligaciones), y de cómo, en sus propias palabras, el pueblo "se hizo de saberes no formales que le permitieron enfrentar situaciones, retos y prácticas de la vida cotidiana, e incluso negociar con las autoridades y otros grupos sociales" (p. 9). Ríos Zúñiga, al igual que todos los autores de este volumen, examinó a fondo prácticamente toda la bibliografía existente sobre cada uno de los temas. Los autores tuvieron cuidado de explicar (en notas al pie de página) conceptos, términos y las referencias académicas necesarias.

La presentación de Juan Leyva da el tono al libro, es decir, nos permite saber que esta obra es fruto de un trabajo exhaustivo, construido sobre una base lógica y detallada. Leyva inicia su texto con una reflexión sobre la oralidad, de la voz y sus características de tonalidad y volumen, del aspecto sonoro de la expresión y de lo que significaba no saber leer y escribir. Entre los vericuetos de la gramática, los enunciados y otras unidades de análisis discursivo (pp. 55-56), analiza la historia de las comunicaciones verbales de rusos, franceses y españoles.

Gracias a su erudición, aparece una palabra poco utilizada: skaz, que es la recuperación de la voz por medio de la escritura, es decir, lo que rescata la oralidad. Y viene a cuento este 
concepto por el interés en conservar la voz popular de actores ya fallecidos. ¿Cómo conocer la entonación, los gestos que acompañaban a las palabras que tenemos documentadas? Apelando a la imaginación del investigador, sin duda, y realizando un análisis lingüístico como el hecho por Juan Leyva.

Al anticipar el contenido de varios trabajos del libro, Leyva habla del carácter subversivo de la voz popular. No cabe duda de que hubo autores, desde antes de la independencia, como Fernández de Lizardi, que escondían tras el habla popular demandas en contra del gobierno o críticas a la sociedad. Era como disculpar al pueblo sus inconformidades, alegando que no sabía lo que decía al emplear un "tono transgresor" (p. 77). El habla popular, convertido en palabra escrita, daba espacio a los escritores para ampliar la gama de géneros a su disposición, de los cuales el autor enuncia una larga lista.

El capítulo de Rosalina Ríos Zúñiga, "Voces populares en torno a la escuela y los mediadores letrados en la ciudad de México, siglo XIX", encabeza la sección sobre educación formal, aunque el libro hace hincapié más bien en saberes no oficiales. Ella se cuestiona: “¿cuál o cuáles fueron [...] la voz o voces populares que se expresaron ante las prácticas educativas 'modernas' y por qué lo hicieron?". A contrapelo de lo que llama la atención en los archivos (lo negativo), Ríos Zúñiga se enfoca en los documentos en los cuales los padres de familia o vecinos solicitan o exigen el establecimiento de una escuela, reclaman un mejor maestro o demandan "que se educaran por igual niños y niñas" (pp. 90-91).

Interesa mucho este tipo de documentos, pues es raro ver una solicitud de educación igual para ambos sexos. El que las niñas no aprendieran sólo labores consideradas en la época propias de su sexo parece poco menos que revolucionario en este periodo. Como Ríos Zúñiga observa, durante la primera mitad del siglo XIX, "el esfuerzo por educar a las mayorías parece provenir más del interés de las élites que de aquéllas" (p. 101). Sin duda es correcta esta conclusión, pues los ilustrados se percataron de la necesidad de educar al pueblo mucho antes de que a éste se le ocurriera.

Sabemos que para desempeñar un oficio se hacía un contrato de aprendiz, y para ser oficinista se empleaba gratuitamente, haciendo méritos, hasta lograr una plaza, en vez de buscar una educación superior. Ríos Zúñiga complementa su tema con información sobre la carencia de fondos para el sustento de las escuelas, lamento que atraviesa todo el siglo XIX y el xx. Privar a los niños de la posibilidad de aprender el habla y la escritura cultos, por no poder mantener abierta la escuela o pagar el sueldo del maestro, fue el pan de todos los días. El resultado fue un gran número de adultos sin habilidades básicas, futuros clientes de las escuelas nocturnas o dominicales.

Quejarse del maestro ha sido pasatiempo nacional. Son muy jóvenes o demasiado viejos, faltistas y desobligados, o liberales radicales o conservadores retrógrados, ignorantes, violentos, pegalones, seductores o borrachos. Esa primera mitad del siglo fue la de los tiempos de 
Los mexicanos pintados por sí mismos, cuando ser pedagogo era sacarle la última droga al diablo, pidiéndole prestado a cambio de su alma. Vendrían mejores tiempos, de maestros apóstoles durante el porfiriato, y de maestros secretarios y de extensión agrícola y política después de la Revolución.

Desde que en la década de 1860 se dejó de requerir la enseñanza de la doctrina cristiana en las escuelas públicas del Distrito Federal y de los territorios, hubo maestros observantes de la ley, otros que enseñaban la doctrina sin temer ningún castigo, y de todos los matices intermedios. La escuela reflejaba el campo de batalla que era la sociedad misma. Ríos Zúñiga recorre las quejas, representaciones, cartas y oficios en los que los reclamos populares, a veces en sus propias palabras y a veces por medio de alguna autoridad o letrado, hacían llegar a la superioridad el mensaje de su descontento. La autora identifica los puentes entre las culturas que va examinando y la manera como se cruzan, con ayuda de la palabra escrita.

El capítulo de Gabriela Pellegrino, "La escuela elemental en el horizonte de las repúblicas de indios de Oaxaca en el siglo XIX", nos regala la historia de la importancia que los pueblos asignaban a dicha escuela. Tenemos muchos testimonios del rechazo a estos establecimientos, no tantos de su aceptación (Smith, 2012). Pellegrino reconoce que estos grupos, que muchas veces vivían muy aislados, buscaban educar a uno o dos de los suyos para representarlos en la ciudad, o para defenderlos jurídicamente en litigios de todo tipo, sobre todo contra los vecinos. No era el acceso a la cultura universal lo que les importaba.

Dominar las letras era un mecanismo de defensa de estos pueblos indígenas frente a un mundo agresivo e invasor. Era cuestión de supervivencia. Pero no todos los pueblos lo percibían con la misma intensidad: unos insistían en la exigencia de tener escuela; otros fueron indiferentes, o de plano rechazaban el establecimiento de ésta, sobre todo si el maestro era foráneo y si su presencia constituía un atentado a los usos y costumbres locales. Si se casaba con una lugareña, incluso podía exigir tierras para sembrar, disminuyendo así las disponibles para los demás.

La enseñanza de los oficios era una intersección entre el trabajo manual y las letras. Los aprendices se instruían haciendo, pero andando el siglo XIX, se comenzó a creer que aprender a leer y a escribir elevaría el nivel moral de los empleados de un taller o fábrica, quienes podían gastar sus horas de ocio con lecturas que cultivaran su espíritu, en vez de estar a los gritos y contando malos chistes obscenos en la cantina. A tal punto fue esto así, que en una memoria del gobierno federal de 1849 se propuso la creación de gabinetes de lectura, justamente para que los obreros no fueran a las cantinas.

Leer y escribir daría entrada a las buenas maneras, a la urbanidad, a la cortesía, a la responsabilidad hacia el trabajo, a ser puntual, respetuoso, honrado, y los hombres aprenderían a contener sus ímpetus naturales por el desorden, las mujeres y la borrachera. Los ilustrados, y sus herederos los liberales, creyeron que las letras eran una vía para moralizar a la sociedad, 
pues libraban al individuo de vicios mediante el uso de la razón. Nos recuerda la ilusión creada por la enseñanza del dibujo que también, pensaban los ilustrados, llevaría a los artesanos a hacer mejor su trabajo, y a las mujeres les llenaría sus horas de ocio de deliciosa creatividad, dando por resultado una sociedad más industriosa y, para las mujeres, más feliz.

En el capítulo "La ¿autogestión? educativa en los grupos laborales: del gremio a las organizaciones obreras del siglo XIX", Sonia Pérez Toledo reseña las publicaciones que fueron hechas para los trabajadores mexicanos, tanto maestros como aprendices. Ella encontró que los artículos traducidos que se originaron en el extranjero no contenían información pertinente para un taller mexicano, pues los utensilios, ingredientes, fórmulas químicas, pinturas y tintes no eran iguales a los utilizados en México, como tampoco los precios y las condiciones sociales. Eran artículos que no servían ni tenían interés para los lectores obreros. Pocos aprendices tenían ganas de leer el periódico después de su turno de catorce horas en la fábrica, aunque supieran leer, y aunque les prestaran un ejemplar, pues únicamente deseaban descansar.

El capítulo de Claudia Rivas, "Educación y progreso. La enseñanza formal de las artes y los oficios en Guadalajara, 1842-1900", va por el mismo camino. También en Guadalajara las autoridades educativas querían combatir la vagancia, favorecer el desarrollo industrial al evitar la importación de manufacturas, crear buenos y obedientes creyentes y ciudadanos (lo de siempre), la panacea de una república estable, próspera y feliz. Puras ilusiones, pues el Estado no financió el proyecto. La escuela de artes y oficios recibía dinero, en gran parte, de la caridad particular. Para variar, el gobierno proponía un plan, pero sin los recursos necesarios para llevarlo a cabo. Lo que sí deseaba era controlar el tipo de enseñanza dada a los artesanos, y para eso lo ideal era sacarlos de los talleres, donde aprendían bajo la dirección de maestros de los oficios, y meterlos a escuelas, con profesores aprobados por el ayuntamiento, que les enseñarían a leer y a escribir. Es decir, que mezclarían el aprendizaje manual con el libresco.

Este plan no tuvo éxito y los jóvenes continuaron asistiendo a los talleres donde aprendían por imitación, a lo largo de varios años, durante los cuales vivían con el maestro, bajo su disciplina, fuera bueno o no para la enseñanza, sin ninguna garantía de buen trato, como tampoco lo había en la escuela. Al Estado le interesaba romper el poder cooperativo de los ex gremios, pero no hubo ninguna posibilidad de hacerlo, mientras no estableciera y financiara una verdadera educación técnica. Los artesanos siguieron perteneciendo a un mundo ágrafo, jerarquizado, tradicional y religioso.

Los espacios públicos facilitaron el encuentro de las dos culturas (la culta y la popular) a lo largo de la historia de México; muchas veces los escritos que pertenecían al ambiente académico alcanzaron a salir a la calle. Justamente en ésta convivían letrados e iletrados, ricos y pobres, hombres y mujeres. Y lo hacían todavía más cuando había fiestas, como proclamar el triunfo de la Revolución de Ayutla, tema que estudió Regina Tapia en "La voz popular en 
'los vivas' del 13 de agosto de 1855 o De cómo las élites y el pueblo se unieron en un mismo acto político". En esa fecha y en una acción más que simbólica en contra del gobierno, la multitud destruyó la imprenta del periódico El Universal, por lo que el cruce entre letras y voces no siempre fue apacible. En esa ocasión ganaron la voz y la violencia.

Al dar un salto de treinta y siete años, otro movimiento popular, el estudiantil de 1891, dio motivo para la reunión conjunta, nuevamente en la calle, de estudiantes y de obreros. Hubo antecedentes de rebeliones estudiantiles durante la década de 1840, cuando los alumnos de medicina alebrestaron a los de minería para denunciar, a voz en cuello, la disciplina que imponían las autoridades. En el caso porfirista, estudiantes y grupos populares se aliaron en un movimiento antirreleccionista de forma mutuamente ventajosa, ya que el pueblo hizo presión, aportando un buen contingente de personas y los estudiantes los textos explicativos de su inconformidad. Se sumaron dos elementos esenciales para una protesta: la multitud, que impone por la fuerza, y la pluma, que convence tanto como la espada. Ambos sectores buscaron legitimar sus demandas con estrategias compartidas.

En este juego de complementariedad, los periodistas desempeñaron un papel clave, pues se constituyeron en puente entre la palabra escrita y aquellos con voz, pero sin letras. Los hombres de pluma consolidaron las ideas expresadas por los trabajadores, haciéndolas comprensibles al público lector, y al mismo tiempo influyeron en sus conceptos políticos. El papel de los periodistas es especialmente importante en este episodio, gracias al cual hubo comunicación entre ambos sectores. Como señala Alberto Quintero, los estudiantes y los obreros "compartían espacios comunes de vivienda, diversión y esparcimiento" (p. 265). Es uno de varios ejemplos de alimentación cruzada de un grupo hacia otro que se menciona a lo largo del libro.

Esta convivencia se muestra también en el capítulo de José Rodrigo Moreno sobre los gritos de independencia entre 1887 y 1900, en el que explica cómo, durante estas celebraciones, se fue incrementando el odio a los españoles. La relación precisa entre escritura y voz popular es menos obvia en este caso, pero lo infeccioso del sentimiento de rechazo hacia los gachupines desempeñó el mismo papel de transmitir un mensaje común a ambos medios.

Procurar acallar el profundo descontento popular con el control gubernamental de las fiestas patrias es el tema de Florencia Gutiérrez, quien analiza la manera como se soslayó a los gremios y asociaciones que tradicionalmente organizaban las fiestas patrias, para someterlos a un guión preparado por el gobierno, el cual subrayaba la concordia y la paz social bajo la benevolencia de Porfirio Díaz.

El libro coordinado por Ríos Zúñiga y Leyva ilustra otra faceta del tema de la tensión entre cultura letrada e iletrada en la sección "Disidencia y humor en la prensa". Dando un gran salto temporal hacia atrás, del porfiriato se pasa a los años anteriores a la independencia, con un análisis del Diario de México. Se examina el propósito de un periódico ilustrado de la época: 
comunicar el conocimiento útil y educar al pueblo, incluso el analfabeto. Las cartas de denuncia publicadas en este periódico están escritas en el lenguaje popular, dando lugar a todo tipo de comentarios negativos. Pero escudarse en la "ignorancia" del pueblo era una buena estrategia para una prensa que tenía prohibido publicar noticias del extranjero y de política local. Desde el punto de vista histórico, el ejemplo del Diario de México se considera uno de los primeros cruces entre cultura letrada e iletrada, dando voz a un pueblo que tenía eso, pero nada más. Desde luego que algunas cartas podían ser inventadas, pero la idea era reflejar el sentir popular. Pasaba lo mismo en el teatro de títeres, en el que el habla popular daba lugar a un buen intercambio de ideas, de oportunidades de crítica social y política, de expresar resentimientos y reclamos. Los titiriteros aprovecharon sus discursos para trasmitir al pueblo el conocimiento ilustrado práctico, que tanto importaba a los pensadores de la época. Así se estableció un contacto vibrante y dramático entre cultura escrita, mediante el guión, y el público ágrafo.

Tres cuartos de siglo después, como explica Leyva, otro periódico, El Valedor, se convirtió en mediador entre los dos grandes sectores de la población, los que sí poseían las letras y los que no. Los "chistes, consignas, refranes y diálogos callejeros" que son el objeto de estudio de Leyva, dan pistas acerca de "la voz popular como enlace estilístico, ético y político" (pp. 425, 429). Para este periodo, calcula que 17 por ciento de la población sabía leer, así que el número de individuos que podía acercarse personalmente a un texto escrito, no mediante la lectura en voz alta, se había incrementado en comparación con principios del siglo (p. 460). Leyva examina la influencia del aumento de lectores, y de cómo llegaron a sentir que el periódico había sido creado para hacer valer su voz (p. 477).

El robo en 1853, analizado por Francisco Beltrán Abarca, caracteriza la inseguridad e impunidad de la época y la reacción popular; respecto de la lectura como salvación moral de las prostitutas; sólo falta decir que formaba parte de la misma idea, es decir, que ingresar a la cultura escrita elevaba el nivel moral de quien lo hacía. Esta creencia aun persiste con nosotros, a pesar de las evidencias en contra.

Pasó algo similar con el concepto de la llustración. Cuando todo el pueblo tenga ropa para cubrir su desnudez, decían los publicistas de la segunda mitad del siglo XVIII, ese pueblo será feliz. Prácticamente todo el mundo tiene con qué vestirse hoy en día, y esa felicidad, la común, no la individual, no se ve en ninguna parte. Cuando todos conozcan sus derechos y obligaciones, opinaban, igualmente serán felices. Y tampoco ha ocurrido así.

Los anhelos de los ilustrados no se cumplieron. Introducir al pueblo a la cultura escrita no ha sido una panacea. Se ha enriquecido la alta cultura con la incorporación de la manera de vivir popular, pero el pueblo se ha beneficiado poco de la cultura académica o formal. Esa felicidad que buscamos, o esa sociedad perfecta, lo sabemos hoy, es intangible e inalcanzable. 
Lo que reseña este libro es el esfuerzo que se hizo por combinar las dos culturas, la letrada y la iletrada, con la esperanza de democratizar al país, es decir, de promover la igualdad social. Estamos lejos de ello. Pero el libro recrea el camino andado y, como tal, forma parte importante del estudio de nuestra historia.

\section{Referencias}

Smith, Benjamin T. (2012), The Roots of Conservatism in Mexico: Catholicism, Society, and Politics in the Mixteca Baja, 1750-1962, University of New Mexico Press, Albuquerque. 